\title{
Oedipism reviewed: a case of bilateral ocular self-mutilation
}

\author{
K. STANNARD,' T. LEONARD, ' G. HOLDER, AND J. SHILLING' \\ From the 'Department of Ophthalmology, St Thomas's Hospital, London, and 'the Regional Unit of \\ Neurophysiology, Brook General Hospital, London
}

Summary A 26-year-old Negro male schizophrenic is described with severe bilateral orbital injuries following attempted self-enucleation. Owing to his psychosis there was difficulty in obtaining a visual acuity and in establishing the cause of his fixed, dilated pupils. A CT scan showed bilateral orbital oedema, with surgical emphysema and haemorrhage. The visual evoked potential (VEP) was present in the right eye but absent in the left. High doses of systemic steroids effected rapid resolution of the orbital swelling and recovery of the vision in the right eye. The effects of self-inflicted injury to the orbital content and the value of sophisticated investigation in this unusual case are discussed.

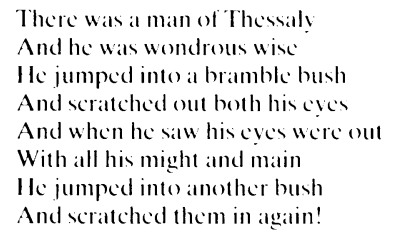

Oedipus is memorable in ophthalmology for his attempt to expiate mortal sin by self-enucleation.' The sacrifice of an eye has traditionally been rewarded by appropriate recompense in mythology. Odin exchanged one of his eyes for permission to drink from the spring of Mimir and thus acquire wisdom and understanding. ${ }^{2}$ Tiresias was blinded for observing Minerva bathing and ironically was rewarded with second sight. "Similar punishment for misdirected thoughts and deeds has endowed ophthalmology with 3 patron saints ${ }^{+}$- Lucia of Syracuse, Triduana, and Medana.

The medical literature contains several welldocumented cases of self-inflicted ocular injury, usually in patients who are insane. 'The mechanism of visual loss may be complicated, including direct trauma or the effects of retrobulbar haemorrhage. Self-enucleation has been performed in at least 20 cases, either by the fingers or by other, often bizarre, instruments."

We describe a schizophrenic patient whose selfinflicted injuries were thought to have provoked Correspondence to Dr K. Stannard. Department of Ophthalmology. St Thomas's Hospital. Iondon SEI 7EII. possible bilateral blindness. The subsequent management was facilitated by emergency visually evoked potential (VEP) and computer-assisted tomography (CT) scan investigations. These findings are discussed.

\section{Case report}

HISTORY

A 26-year-old negro man was admitted to St Thomas's Hospital with bilateral orbital and ocular injuries. Four years previously schizophrenia had been diagnosed after 2 episodes of self-inflicted stab wounds to the chest.

A week before presentation he had consulted an optician, who found a refraction of OD $6 / 9$ unaided, $-1 \cdot()\left(0 /+1 \cdot()()\right.$ at $70^{\circ}$, gave $6 / 6 ;$ OS $6 / 9$ unaided, $-1 \cdot 25 /$ $+1 \cdot(0)$ at $155^{\circ}$, gave $6 / 6$. On admission he was withdrawn and a history could not be obtained from the patient. He had been found by the police with his severe orbital injuries, seemingly unconcerned, but with blood beneath his finger nails and on his hands. His refusal or inability to communicate made accurate assessment of his visual status impossible. 


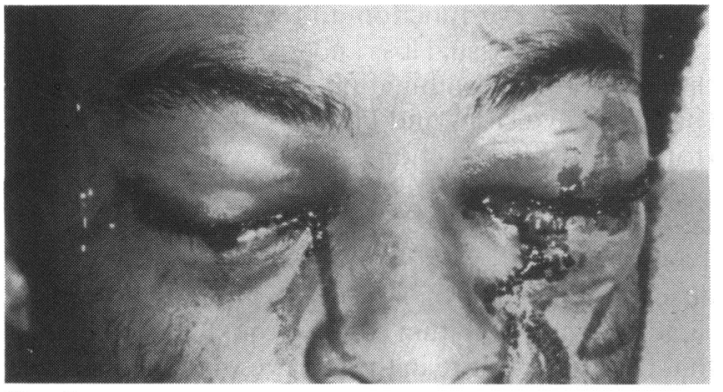

Fig. 1

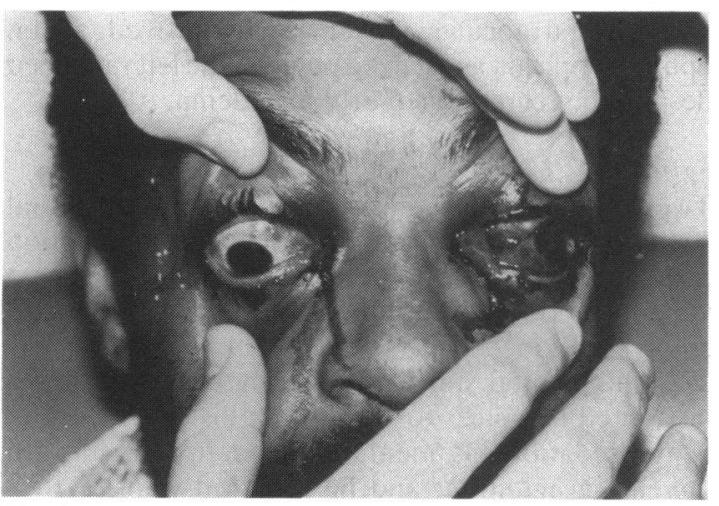

Fig. 2

Figs. 1. 2 Bothlower lids are lacerated, with shallow tears extending from the caruncle, through lower canaliculus to just under the punctum on both sides. There are l cm tertical lacerations of the medial bulbar conjunctiva, with marked subconjunctival haemorrhage on both sides. Notemarked proptosis, with upward, outward displacement of the left e've'

EXAMINATION

There were bilateral periorbital hatematomas. The nature of the external injuries was commensurate with an attempt to gouge out both eyes with the fingers (Figs. 1 and 2). There was bilateral proptosis (right $22 \mathrm{~mm}$, left $26 \mathrm{~mm}$ ), and the left eye was displaced upwards $(4 \mathrm{~mm})$ and outwards $(9 \mathrm{~mm})$. Eye movements, including doll's head reflexes, appeared absent. Both orbits were tense, with increased resistance to retropulsion.

The pupils were fixed and dilated, even with maximal slit-lamp illumination. The corneate and anterior chambers were clear, but intracoular pressures were elevated at right $3.5 \mathrm{mmHg}$. left 4.5 $\mathrm{mmHg}$. On funduscopy there was a small nerve fibre layer haemorrhage at the inferior disc margin in the right. The fundi were otherwise normal. Further examination revealed no other injury, but 2 scars on the anterior chest wall were consistent with the history of previous self-inflicted trauma.

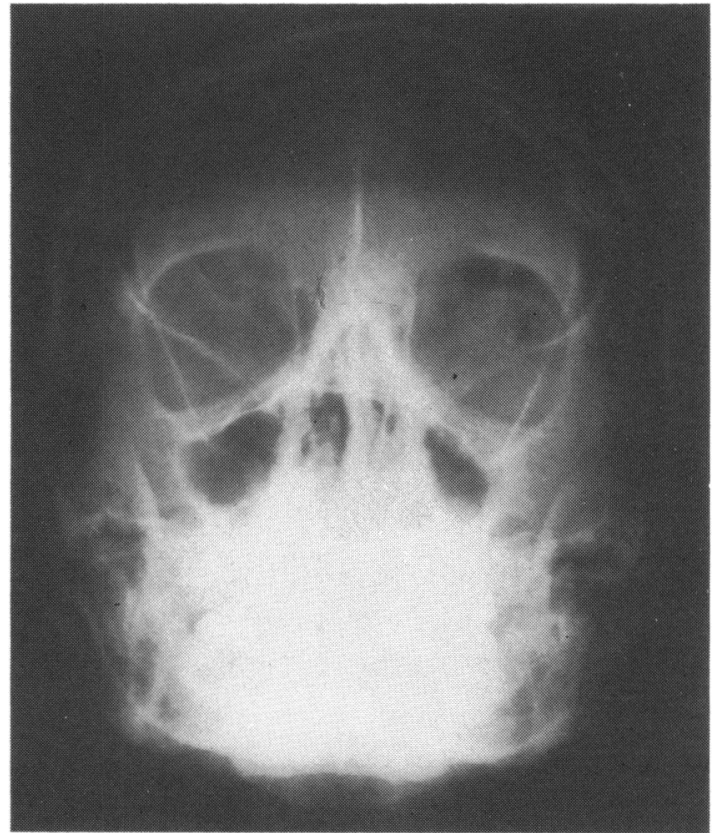

Fig. 3 Plain skull $x$-ray at time of admission. Note gas shadow in leftorbit.

MANAGEMENT

A diagnosis for the cause of the patient's fixed dilated pupils was important in determining the immediate management. His complete failure to acknowledge a light stimulus together with bilateral fixed dilated pupils posed the question whether he was now blind from acute optic nerve injury. A second possibility was the presence of bilateral third nerve palsies, with fixed dilated pupils. The accompanying ophthalmoplegia and ptosis, however, could have been due to the severe orbital congestion rather than a neurological cause.

The possibility of reversible blindness necessitated urgent investigation, since further examination was impossible.

\section{INVESTIGATIONS}

Plain skull $x$-ray (Fig. 3) showed orbital emphysema on the left but no fracture. Orbital CT scan (Figs. 4 , 5) showed bilateral proptosis, worse on the left. The appearance was of lateral displacement of the orbital contents, but a localised haematoma could not be confirmed. No other unsuspected pathology was demonstrated. Coronal views could not be obtained.

Urgent flash VEP examination (Fig. 6) was performed. The right flash VEP was normal. The left flash VEP was absent. Electroretinography had to be abandoned because of poor patient co-operation.

Haematological investigation showed no evidence 


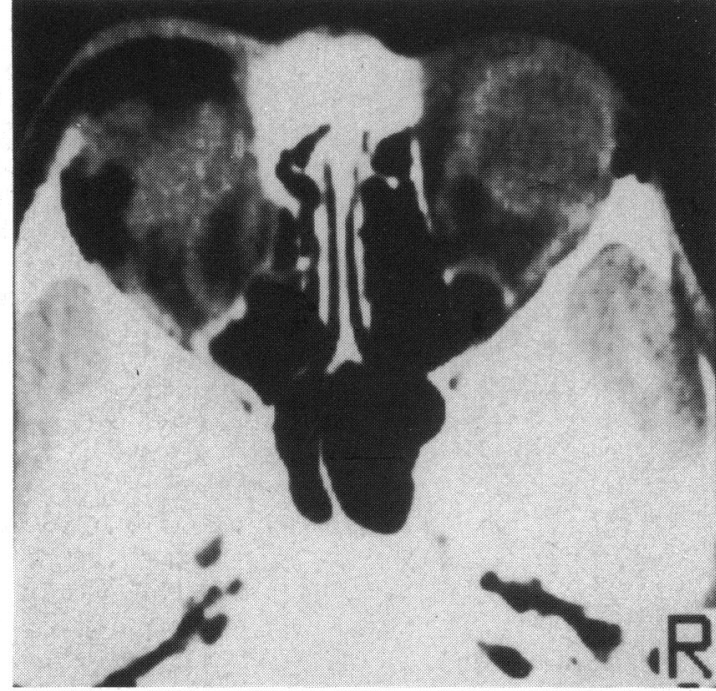

Fig. 4

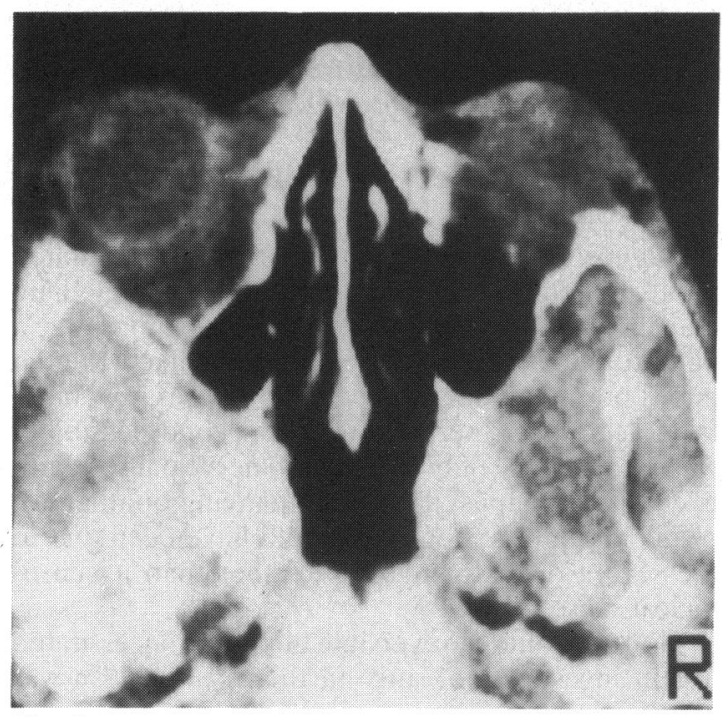

Fig. 5

Figs. 4, 5 CTscan of the orbits one hour after admission. Note optic nerves and ocular muscles are normal in size. Left orbital contents are displaced laterally, and areas of oedema, intraorbital gas, and haemorrhage are shown.

of a bleeding diathesis. The only abnormality was an unexplained raised white cell count $\left(13 \cdot 8 \times 10^{9} / 1\right)$.

\section{DIAGNOSIS}

The investigations suggested bilateral intraorbital oedema, haemorrhage, and emphysema. Compression of the left optic nerve was not proved by the absent VEP. The normal right VEP suggested good optic nerve function and was reassuring. The cause of his left visual loss and fixed dilated pupil was thought to be a combination of optic nerve damage (probably avulsion) and bilateral third nerve palsies from intraorbital traction.

\section{TREATMENT}

To relieve the intraorbital pressure a course of highdose systemic steroids was given. The proptosis rapidly resolved. Within 24 hours funduscopy showed that the visual failure in the left eye was due in part to a central retinal artery occlusion (Fig. 7) secondary to nerve avulsion. The right pupil reaction recovered and the extraocular movements improved. Total ophthalmoplegia and a fixed pupil on the left remained despite the regression of orbital oedema.

\section{PROGRESS}

Twelve hours after admission he had a right visual acuity of $6 / 18$ but the left remained at no perception of light (NPL). In addition to steroids he received systemic and topical antibiotics, acetazolamide, and chlorpromazine.

As his mental state improved he admitted being instructed by voices to scratch out his eyes. Despite heavy sedation his mental state deteriorated with increasing agitation, and he required transfer to a mental hospital.

One week after the injury his right visual acuity was $6 / 9$, the left NPL. The proptosis had resolved, though the left eye remained divergent, with marked limitation of adduction. The left pupil remained fixed and dilated. The right reacted normally to direct illumination but had no consensual response, confirming a left afferent defect. The right fundus was normal, the splinter haemorrhage having resolved, but the appearances of a left central retinal artery occlusion remained. The steroids were rapidly tailed off.

\section{Discussion}

Attempted self-enucleation is an uncommon method of self-mutilation, though several cases have been described. The majority of reported cases are of patients with a psychotic illness, most frequently schizophrenia, but similar injuries have also been reported in patients with obsessive/compulsive neuroses, ${ }^{7}$ and in drug induced psychosis. "Organic mental states including epilepsy," encephalitis, ${ }^{10}$ diabetes, ${ }^{11}$ Lesch-Nyhan syndrome, ${ }^{12}$ and Gilles de la Tourette syndrome ${ }^{1.3}$ may stimulate similar self-injury.

Visual failure due to self-inflicted injury may be a result of penetrating wounds, contusion, traction, or compression of orbital contents from oedema or 


\section{FVEP}

O.D.

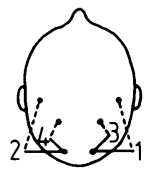

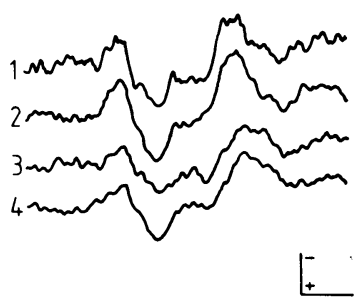

O.S.

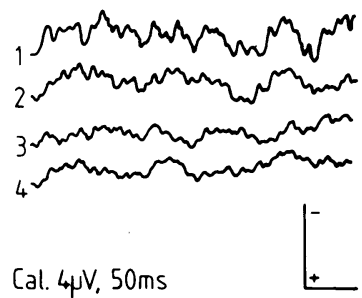

Fig. 6 Right and left eye VEPs. Three hours after admission: Right eye flash stimulation evoked a major positive component at 126-130 milliseconds over both hemispheres, having an amplitude of some 7.0-8.0 microvolts. The preceding negative component occurred at some 92 milliseconds. No consistent significant interhemispheric asymmetry was present. Left stimulation produced no response distinguishable from noise. Note double gain used in recording left response. haemorrhage. Axenfeld ${ }^{1+}$ described how he had performed bilateral enucleation on a cadaver in one minute using only his fingers. The index finger of each hand may be advanced along the medial wall of the orbit to gain access to the retrobulbar space. The eyes are then levered out, bringing extraocular muscles, blood vessels, and optic nerves with them. Unsuccessful attempted self-enucleation in this fashion may cause avulsion of the optic nerve, dislocation of the globe, torn muscles and blood vessels, with consequent orbital oedema and haemorrhage.

Compression of the optic nerve at the orbital apex or within the muscle cone may occur by several mechanisms. The periosteum may be damaged, allowing blood to track along the subperiosteal space towards the orbital apex. Intraorbital bleeding from the torn arteries and veins may cause massive haemorrhage and increased orbital tension. Intraconal haematomas would directly compress the optic nerve.

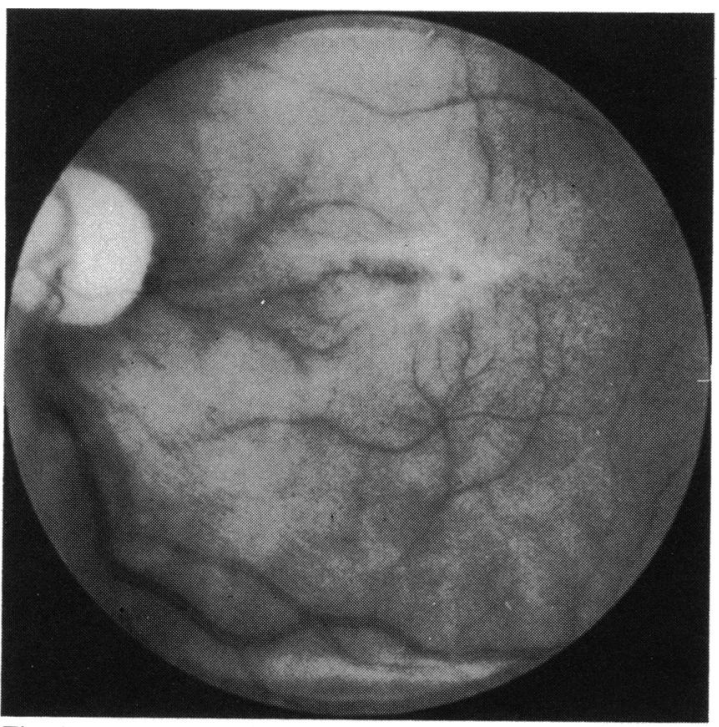

Fig. 7 Left retinal photograph, 72 hours afier admission.
Similar mechanisms are occasionally seen to cause visual loss after surgery. Cosmetic blepharoplasty has been complicated by orbital haemorrhage or subperiostial bleeding tracking back to the orbital apex, causing optic nerve compression. ${ }^{15}$ Orbital and intraconal haemorrhage rarely follows injudicious retrobulbar anaesthesia. Central retinal artery occlusion may follow ethmoidal fracture. ${ }^{16}$ The mechanism has been described as an acute rise in orbital tension due to surgical emphysema.

The management of this schizophrenic patient was complicated by the difficulty of obtaining historical and examination clues to his visual status. The VEP confirmed severely impaired visual function in the left eye but probably normal function in the right. The CT scan excluded an intraconal haemorrhage or massive intraorbital bleeding that might have demanded surgical intervention. The use of these special investigations allowed a more conservative approach to management in this unusual case.

We are indebted to Mr P. D. Trevor-Roper and Mr M. D. Sanders for their advice.

We thank Miss D. Clutterbuck for her secretarial assistance and Mr R. Dewhirst for preparing the photographs.

\section{References}

I Wilson WA. Ocdipism. Am J (Ophthalmol 1955; 40: 56.3-7.

2 Davison IIRE. Gools and Myths of Northern Europe. Harmondsworth: Penguin Books. 1964.

3 Trevor-Roper P. The psychopathic eye. Br J Hosp Med l980) 23: $1.37-4.3$.

4 Dukc-Elder S. Sistems of Ophthalmology. London: Kimpton. 1962: 7: 47(1)-1.

5 Kell Yang 11. Brown GC. Magargal LE. Sclf-inflicted ocular mutilation. Am J Ophthalmol 1981: 91: 658-63.

6 Tapper CM. Bland RC. Danyluk L. Self-inflicted eye injuries and self-inflicted blindness. J Nerv Me'ml Dis 1979; 167: $311-4$.

7 Stinnett JL. Hollender MH. Compulsive self-mutilation. J Nern' Ment Dis 1970): 150: 373-5.

8 Goldsmith W. Self-enucleation: further views. Am J Psychiaury 1973: 130: 329.

9 Sochs J. Automutilatio bulborum. A rare case of self-mutilation in an epileptic. Acta Ophthalmol $(K b /)$ 1948: 26: 451-3. 
10 Goodhart SP. Savitsky N. Self-mutilation in chronic encephalitis. Avulsion of both cychalls and extraction of tecth. Am J Med Sci. 1933: 185: $674-84$.

11 Brown BZ. Self-inflicted injuries of the eye. Trans Pac Coast Otoophthalmol Soc 197(): 51: 267-76.

12 Mizuno T. Yugari Y. Prophylactic effect of L-5-Hydroxytryptophan on self-mutilation in the Lesch-Nyhan syndrome. Neturopaediatric 1975; 6: 13

13 Van Woert MH. Yip LC. Balis MF. Purine phosphoribosvl transferase in Gilles de la Tourette syndrome. $N$ Engl J Med 1977: 296: 210 .

If Axenfeld T. Über Luxation. Zerstorung und Herausreissung des Augapfels als Selbstverstummelung bei Geisteskranken. Z Augenheilkd 1899: 1: 128.

15 Kelly PW. May DR. Central retinal artery occlusion following cosmetic blepharoplasty. Br.J Ophthalmol 1980; 64: 918-22.

16 Linberg JV. Orbital emphysema complicated by acute eentral retinal artery occlusion: case report and treatment. Ann Ophthal 1982: 14: 747-9. 